\title{
Design thinking e o desenvolvimento de competências dos profissionais do século XXI
}

\author{
Design thinking and the development of competencies for 21 st century professionals \\ Design thinking y el desarrollo de competencias de los profesionales del siglo XXI
}

Recebido: 12/04/2021 | Revisado: 17/04/2021 | Aceito: 22/04/2021 | Publicado: 08/05/2021

\author{
Lucia Cuque \\ ORCID: https://orcid.org/0000-0002-3016-8221 \\ Pontifícia Universidade Católica de São Paulo, Brasil \\ -mail: lucia.cuque@gmail.com \\ João Mattar \\ ORCID: https://orcid.org/0000-0001-6265-6150 \\ Pontifícia Universidade Católica de São Paulo, Brasil \\ E-mail: joaomattar@gmail.com
}

\begin{abstract}
Resumo
O objetivo deste artigo é avaliar se o uso do design thinking em ambientes corporativos contribui para o desenvolvimento das competências necessárias aos profissionais do século XXI. Este artigo pode contribuir para estimular a utilização do design thinking nas organizações. Sua originalidade está no entendimento da perspectiva dos profissionais que atuam diretamente com a abordagem sobre o desenvolvimento das competências profissionais, seja por meio da moderação ou participação nas sessões, seja por meio de ações de educação corporativa que utilizam o design thinking como metodologia ativa de ensino. O estudo envolveu uma revisão de literatura e uma pesquisa de campo. A metodologia geral da pesquisa foi aplicada, exploratória, de campo e com abordagem qualitativa. A coleta de dados envolveu nove entrevistas semiestruturadas, cujo roteiro seguiu as características das entrevistas responsivas (Rubin \& Rubin, 2011). A análise dos dados seguiu três critérios de codificação propostos por Saldaña (2013). Os resultados apontaram que o design thinking contribui para o desenvolvimento das competências pessoais e sociais dos profissionais, quando utilizado como metodologia ativa de ensino-aprendizagem nas ações de educação corporativa e na resolução de conflitos, busca de soluções e concepção de novos produtos e serviços. Outras conclusões são que o mindset fixo pode interferir negativamente no desenvolvimento das competências, e a conexão do conteúdo e da abordagem de ensino com o mundo real e prático demonstra ser fundamental para o aprendizado e desenvolvimento dos profissionais.
\end{abstract}

Palavras-chave: Aprendizagem experiencial; Educação corporativa; Habilidades; Metodologias ativas; Mindset.

\begin{abstract}
The objective of this article is to evaluate whether the use of design thinking in corporate environments fosters the development of the skills needed by 21 st century professionals. This article can help to encourage the use of design thinking in corporations. Its originality lies in the understanding of the view of professionals who work directly with the approach on the development of professional skills, either by moderating or participating in sessions, or through corporate educational activities that use design thinking as an active teaching methodology. The study involved literature review and field research. The general research methodology was applied, exploratory, field and with a qualitative approach. The data collection included nine semi-structured interviews whose script followed the responsive interview model (Rubin \& Rubin, 2011). The data analysis was based on the three codification criteria proposed by Saldaña (2013). The results showed that design thinking promotes the development of the professionals' personal and social skills when used as an active teaching-learning methodology in corporate educational activities, as well as when resolving conflicts, searching solutions and designing new products and services. Other conclusions are that a fixed mindset might have a negative effect in the development of competencies, and the connection between the content and teaching approach and the real and practical world is essential for the learning and development of the professionals.
\end{abstract}

Keywords: Experiential learning; Corporate education; Skills; Active methodologies; Mindset.

\section{Resumen}

El objetivo del presente artículo es evaluar si el uso del pensamiento de diseño (design thinking) en entornos corporativos contribuye al desarrollo de las competencias que necesitan los profesionales del siglo XXI. Este artículo puede contribuir a estimular el uso del pensamiento de diseño en las organizaciones. Su originalidad reside en la comprensión de la perspectiva de los profesionales que trabajan directamente con el enfoque sobre el desarrollo de las habilidades profesionales, ya sea a través de la moderación o la participación en las sesiones, o a través de acciones de educación corporativa que utilizan el pensamiento de diseño como una metodología de enseñanza activa. El estudio incluyó una revisión de la literatura y una investigación de campo. La metodología de investigación general fue 
aplicada, exploratoria, de campo y con un enfoque cualitativo. La recopilación de datos comprendió nueve entrevistas semiestructuradas, planeadas para seguir las características de las entrevistas de respuesta (Rubin \& Rubin, 2011). El análisis de los datos siguió tres criterios de codificación propuestos por Saldaña (2013). Los resultados mostraron que el pensamiento de diseño contribuye al desarrollo de las habilidades personales y sociales de los profesionales, cuando se utiliza como metodología de enseñanza-aprendizaje en acciones de educación empresarial y en la resolución de conflictos, búsqueda de soluciones y diseño de nuevos productos y servicios. Otras conclusiones son la interferencia negativa que el mindset fijo puede tener en el desarrollo de las competencias, y como la conexión del contenido y el enfoque de la enseñanza con el mundo real y práctico son fundamentales para el aprendizaje y el desarrollo de los profesionales.

Palabras clave: Aprendizaje experiencial; Educación corporativa; Habilidades; Metodologías activas; Mindset.

\section{Introdução}

Os impactos trazidos ao trabalho pela Quarta Revolução Industrial (4IR), caracterizada pela internet móvel mais onipresente, sensores menores e mais poderosos, inteligência artificial e machine learning, dentre outras, estão rapidamente influenciando trabalhadores e empresas em todo o mundo, segundo o World Economic Forum (WEF, 2018). Nesse cenário, o trabalho é transformado em uma atividade de natureza mutável que demanda novas competências dos profissionais. Dos trabalhadores, é exigida a sistemática adaptação a novos métodos, organização e ferramentas de trabalho (Gonzalez Vazquez et al., 2019). Para a OECD (2018), na economia global, as habilidades dos profissionais determinam em grande parte a competitividade e a capacidade de impulsionar a inovação, além de preparar as pessoas para empregos de boa qualidade.

Diversos organismos internacionais apresentam um conjunto de competências pessoais e sociais, também chamadas de competências ou habilidades transversais, life skills, soft skills, non-cognitive, social and emotional ou 21st century skills, necessárias aos cidadãos, para o enfrentamento dos desafios trazidos pela tecnologia no trabalho (EC, 2018; OECD, 2018; WEF, 2018).

A demanda por desenvolvimento de competências impulsionou a Comissão Europeia (EC, 2018) a alterar a orientação da educação de aprendizagem para competências. A orientação para as competências demanda das ações de educação e treinamento abordagens interdisciplinares, estilos de aprendizado e ensino interativos, uma combinação entre as aprendizagens formal, informal e não formal, uma vez que a aprendizagem ocorre de variadas formas e em todos os ambientes da organização (EC, 2018; Reisch \& Dalmau, 2020), maior participação das partes interessadas, não necessariamente relacionadas à educação, um novo papel do facilitador e novas abordagens de avaliação (EC, 2018).

O design thinking tem como característica o estímulo à inovação por meio da colaboração, empatia, interatividade, além de ser centrado nas pessoas. Pesquisas têm sido empreendidas no sentido de trazer o design thinking para a prática de ensino-aprendizagem, concentrando a instrução no aluno, transformando-o em uma opção de metodologia ativa de ensinoaprendizagem eficaz e amplamente acessível. Gerar novas ideias e explorar soluções alternativas, em vez de escolher entre as alternativas existentes, é um dos objetivos do design thinking enquanto metodologia de ensino (Lynch et al., 2019).

Para a seleção do objeto deste estudo, partiu-se do pressuposto de que o design thinking, por ser uma abordagem humanista destinada à resolução de problemas complexos e à concepção de produtos e serviços, poderia contribuir para o desenvolvimento de algumas das competências apontadas como necessárias aos profissionais que atuam na 4IR.

O problema que norteou esta pesquisa foi o entendimento, segundo o ponto de vista dos entrevistados e da teoria, se o design thinking poderia promover o desenvolvimento de competências necessárias aos profissionais. Com o objetivo de refletir sobre possíveis respostas à questão da pesquisa, algumas hipóteses foram elaboradas. São elas:

a) a abordagem design thinking, aplicada na concepção de novos produtos, serviços ou na resolução de problemas, contribui, junto aos profissionais envolvidos em sua dinâmica, para o desenvolvimento das competências do 
século XXI identificadas como necessárias ao profissional, independentemente das ações oferecidas pela área de educação corporativa da empresa;

b) a abordagem design thinking, enquanto metodologia de ensino-aprendizagem, quando aplicada em ações de educação corporativa, gera, segundo a opinião dos entrevistados, resultados superiores aos resultados das ações que utilizam metodologias tradicionais;

c) os mindsets — individual e organizacional — interferem no desenvolvimento das competências dos profissionais.

O objetivo geral da pesquisa foi avaliar se a utilização da abordagem design thinking, em ações de educação corporativa, resolução de problemas ou na concepção de novos produtos e serviços, contribui para o desenvolvimento de competências nos profissionais. Esta pesquisa contou com os seguintes objetivos específicos:

a) compreender a correlação que o entrevistado faz entre, de um lado, seu autodesenvolvimento e a(s) competência(s) mencionada(s) por ele como necessária(s) aos profissionais que atuam com design thinking, e, de outro, sua participação nas sessões e/ou processos de design thinking;

b) compreender a correlação que o entrevistado faz entre os resultados da metodologia de ensino-aprendizagem tradicional e a abordagem de ensino-aprendizagem design thinking, segundo sua experiência pessoal;

c) compreender se, na opinião pessoal do entrevistado, fatores como o mindset individual ou mindset organizacional podem interferir no desenvolvimento de competências, tais como: pensamento crítico, empatia, comunicação, colaboração, criatividade e inovação.

\section{Fundamentação Teórica}

\subsection{Competências necessárias ao profissional}

$\mathrm{Na}$ economia do saber, o sujeito é um ator e espera-se que ele vá além do prescrito, que saiba agir e escolher uma conduta. O profissional competente é aquele que, a partir de uma abordagem combinatória entre o conjunto de recursos incorporado à sua pessoa (conhecimentos, habilidades, qualidades, experiências, capacidades cognitivas, recursos emocionais etc.) e o conjunto de recursos do seu meio (bancos de dados, redes de especialistas e de documentos etc.), sabe agir com equilíbrio em determinado contexto que se apresenta. (Le Boterf, 2003).

Nos quadros de referência internacionais de competências, o termo "competência" às vezes é classificado como "habilidade", dependendo do documento. No relatório 21 st century skills and competences for new millennium learners in OECD countries, Ananiadou e Claro (2009) relatam que os termos "habilidade" e "competência" são utilizados de maneira intercambiável nos países pesquisados, e, em função disso, incluíram ambos os termos na pesquisa que gerou o relatório. Este artigo segue esse entendimento sobre competências e habilidades.

O Quadro 1 fornece uma visão ampla das competências, habilidades e atitudes mencionadas como necessárias, no contexto do trabalho, por quatro estruturas de referências internacionais. 
Quadro 1 - Visão geral de algumas das estruturas de competência internacionais.

\begin{tabular}{|c|c|c|c|}
\hline WEF - 2018 & $\begin{array}{l}\text { EUROPEAN } \\
\text { COMMISSION — } 2018\end{array}$ & $\begin{array}{l}\text { P21 - } 2019 \\
\text { Battelle for Kids }\end{array}$ & OECD.Stat -2019 \\
\hline $\begin{array}{l}\text { Análise e avaliação de } \\
\text { sistemas }\end{array}$ & Aprendizado ativo & Adaptabilidade & $\begin{array}{l}\text { Análise de controle de } \\
\text { qualidade }\end{array}$ \\
\hline $\begin{array}{l}\text { Aprendizagem ativa e } \\
\text { estratégias de aprendizagem }\end{array}$ & $\begin{array}{l}\text { Capaz de lidar com a } \\
\text { incerteza e o estresse }\end{array}$ & Alfabetização ambiental & Análise de operações \\
\hline $\begin{array}{l}\text { Criatividade, originalidade } \\
\text { e iniciativa }\end{array}$ & $\begin{array}{l}\text { Ciência, tecnologia e } \\
\text { engenharia }\end{array}$ & Alfabetização cívica & Análise de sistemas \\
\hline Inteligência emocional & Colaboração & Alfabetização em saúde & Aprendizado ativo \\
\hline $\begin{array}{l}\text { Liderança e influência } \\
\text { social }\end{array}$ & $\begin{array}{l}\text { Competência em } \\
\text { alfabetização }\end{array}$ & $\begin{array}{l}\text { Alfabetização financeira, } \\
\text { econômica, empresarial }\end{array}$ & $\begin{array}{l}\text { Audição ativa e } \\
\text { conversação e escrita }\end{array}$ \\
\hline $\begin{array}{l}\text { Pensamento analítico e } \\
\text { inovação }\end{array}$ & Comunicação & Autodireção & Avaliação de sistemas \\
\hline $\begin{array}{l}\text { Pensamento e análise } \\
\text { críticos }\end{array}$ & Criatividade e inovação & Colaboração & Ciência \\
\hline $\begin{array}{l}\text { Projeto e programação de } \\
\text { tecnologia }\end{array}$ & Digital & Comunicação & Compreensão de leitura \\
\hline $\begin{array}{l}\text { Raciocínio, resolução de } \\
\text { problemas e ideação }\end{array}$ & Empatia & Consciência global & Coordenação \\
\hline \multirow{24}{*}{$\begin{array}{l}\text { Solução de problemas } \\
\text { complexos }\end{array}$} & Estratégias de aprendizado & Criatividade & Design de tecnologia \\
\hline & Influência social & Flexibilidade & Estratégias de aprendizado \\
\hline & Matemática & Habilidades sociais & $\begin{array}{l}\text { Gerenciamento de recursos } \\
\text { materiais }\end{array}$ \\
\hline & Multilíngue & Habilidades transculturais & Gerenciamento de tempo \\
\hline & Negociação & Iniciativa & $\begin{array}{l}\text { Gestão de recursos } \\
\text { financeiros }\end{array}$ \\
\hline & Pensamento crítico & Inovação & $\begin{array}{l}\text { Gestão de recursos } \\
\text { humanos }\end{array}$ \\
\hline & Resiliência & Liderança & Habilidades de matemática \\
\hline & Solução de problemas & Literacia da informação & Instalação \\
\hline & Tomada de decisão & Literacia midiática & Instrução \\
\hline & & Pensamento crítico & $\begin{array}{l}\text { Julgamento e tomada de } \\
\text { decisão }\end{array}$ \\
\hline & & Prestação de contas & $\begin{array}{l}\text { Manutenção de } \\
\text { equipamento }\end{array}$ \\
\hline & & Produtividade & Monitoramento \\
\hline & & Responsabilidade & Monitoramento de operação \\
\hline & & Solução de problemas & Negociação \\
\hline & & & Operação e controle \\
\hline & & & Orientação de serviço \\
\hline & & & Pensamento crítico \\
\hline & & & Percepção social \\
\hline & & & Persuasão \\
\hline & & & Programação \\
\hline & & & Reparação \\
\hline & & & $\begin{array}{l}\text { Resolução de problemas } \\
\text { complexos }\end{array}$ \\
\hline & & & Seleção de equipamentos \\
\hline & & & Solução de problemas \\
\hline
\end{tabular}

Fonte: Autores, baseados em WEF (2018), EC (2018), Battelle for Kids (2019) e OECD.STAT (2019) 


\subsection{Competências pré-selecionadas pelos autores}

Com o objetivo de compreender se o mindset individual ou organizacional pode interferir no desenvolvimento de competências, algumas competências foram selecionadas, como pensamento crítico, empatia, comunicação, colaboração, criatividade e inovação. As definições das competências utilizadas neste artigo foram extraídas das estruturas internacionais de competência mencionadas no Quadro 1.

\section{Colaboração}

Demonstrar capacidade de trabalhar de forma eficaz e respeitosa com diversas equipes. Exercer flexibilidade e vontade de ajudar para realizar os compromissos necessários para alcançar um objetivo comum. Assumir responsabilidade compartilhada pelo trabalho colaborativo e valorizar as contribuições individuais feitas por cada membro da equipe. (Battelle for Kids, 2019, p. 5, tradução nossa).

\section{Comunicação}

Articular pensamentos e ideias efetivamente usando habilidades de comunicação oral, escrita e não verbal em uma variedade de formas e contextos. Ouvir efetivamente, decifrar o significado, incluindo conhecimentos, valores, atitudes e intenções. Usar a comunicação para diversas finalidades (por exemplo, para informar, instruir, motivar e persuadir). Utilizar várias mídias e tecnologias e saber como julgar sua eficácia, prioridade, bem como avaliar seu impacto. Comunicar-se efetivamente em diversos ambientes (incluindo multilíngue). (Battelle for Kids, 2019, p. 5, tradução nossa).

\section{Criatividade}

Essas características estão associadas à "criatividade", que é um processo tipicamente de imaginar possibilidades, criar algo novo, refletir e modificar o que está sendo criado. Em um sentido mais amplo, é uma maneira de interpretar e agir sobre o mundo. O Quadro de Referência usa a frase 'criatividade e inovação' para descrever onde conhecimentos, habilidades e atitudes específicas podem contribuir para o desenvolvimento de novas ideias, abordagens ou outras coisas. As definições do quadro também se referem a habilidades específicas - como pensamento crítico - e atitudes - como curiosidade - que compreendem a criatividade. (EC, 2018, pp. 42-43, tradução nossa).

\section{Empatia}

É a capacidade de entender o mundo da perspectiva de outro - é reconhecida como uma parte importante do conjunto de habilidades de consciência e expressão cultural. Ser capaz de apreciar e valorizar os contextos e as ações - passadas e presentes - de diversas culturas, grupos e nações exige empatia como uma espécie de solução interpessoal de problemas. (EC, 2018, p. 61, tradução nossa).

\section{Inovação}

Atuar em ideias criativas para dar uma contribuição tangível e útil para o campo em que a inovação ocorrerá. (Battelle for Kids, 2019, p. 4, tradução nossa).

\section{Pensamento Crítico}

Usar a lógica e o raciocínio para identificar os pontos fortes e fracos de soluções alternativas, conclusões ou abordagens de problemas. (WEF, 2018, p. 29, tradução dos autores).

\subsection{Abordagem design thinking}

O design thinking é uma metodologia centrada no ser humano que usa técnicas de co-design para lidar com problemas multidimensionais e que não possuem soluções reconhecíveis (Fabri, 2015; Melo \& Abelheira, 2015). O processo de design thinking da d.school, da Universidade de Stanford, é composto por cinco passos, conforme a Figura 1. 
Figura 1 - Os cinco passos do processo de design thinking.

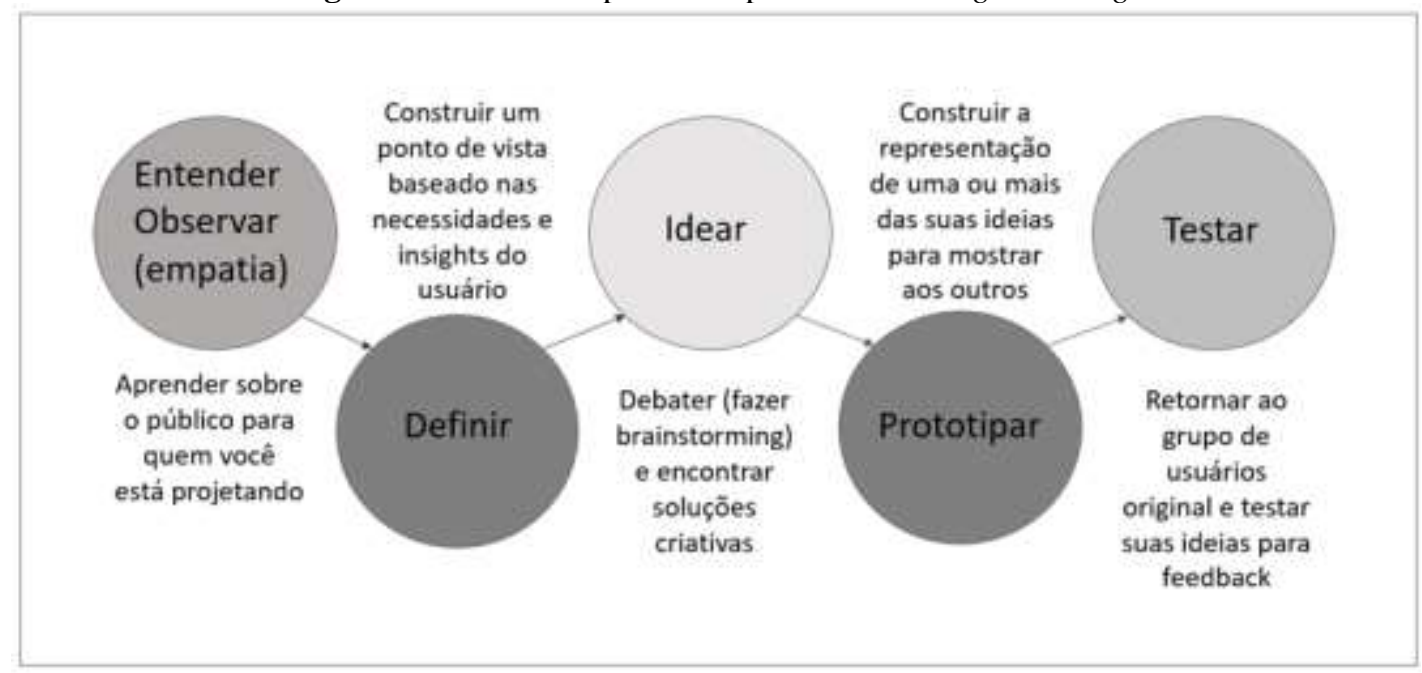

Fonte: Fabri (2015, p. 34, tradução nossa).

As características do design thinking tornam a abordagem eficaz no desenvolvimento da habilidade de empatia, já que utiliza, em seu processo, a observação centrada no ser humano para desenvolvimento de produtos, serviços e estratégias (Lee \& Benza, 2015). Acredita-se que, a partir da combinação entre empatia, criatividade e processos analíticos, a verdadeira inovação surge no modo de resolver problemas. Para Brown (2008), são comuns aos design thinkers: a empatia, o pensamento integrativo, o otimismo, o experimentalismo e a colaboração. O guia Bootcamp Bootleg indica o que chama de begginers mindset, isto é, a mentalidade necessária ao design thinker. O design thinker precisa: não julgar, questionar tudo, ser verdadeiramente curioso, encontrar padrões e ouvir profundamente. (Doorley et al., 2018).

\subsection{Metodologias ativas e aprendizagem experiencial}

Segundo Knowles et al. (2005), no modelo tradicional de ensino os professores e instrutores decidem com antecedência qual conhecimento ou habilidade deve ser transmitido ou desenvolvido e, para tanto, definem os conteúdos, sua sequência lógica de apresentação e a melhor forma ou recurso para transmiti-lo. A andragogia, segundo Knowles et al. (2005, p. 61, tradução nossa), “a arte e a ciência de ajudar os adultos a aprender”, se baseia em algumas premissas, dentre elas, a necessidade de os adultos aprenderem aquilo que precisam saber para lidar com as situações da vida real.

Para Kolb (1984), a aprendizagem é o processo pelo qual o conhecimento é criado por meio da transformação da experiência, segundo o ciclo de aprendizagem experiencial. Segundo Le Boterf (2003, p. 110), o saber empírico resulta da aplicação do ciclo de aprendizagem experiencial, isto é, "a partir da reflexão sobre a experiência concreta, que um trabalho de abstração e de conceitualização poderá ser realizado para ser reinvestido em uma experimentação que dê lugar a uma nova experiência profissional". O aprendizado ocorre em todas as configurações humanas, na escola, no local de trabalho, nos relacionamentos pessoais e nos corredores do mercado (Kolb, 1984), ou seja, a aprendizagem acontece dentro e fora dos ambientes formais de ensino (Filatro et al., 2019).

As metodologias ativas de aprendizagem têm sido desenvolvidas e aplicadas nos ambientes formais de educação e na educação corporativa, pois, diferentemente do ensino tradicional, pressupõem a atividade e a experiência por parte dos alunos (Cavalcanti \& Filatro, 2016; Mattar, 2017). Essas metodologias são mais eficazes do que as tradicionais se o objetivo é avaliar o desenvolvimento de habilidades mais complexas e a conexão do conteúdo com o mundo real (Mattar, 2017). O design thinking, enquanto metodologia ativa, proporciona oportunidades para os alunos saírem de uma posição estática e passiva, por 
meio da participação em cada uma das fases, além de contribuir para um "clima colaborativo de inovação e criatividade na sala de aula - ou nos ambientes virtuais de aprendizagem” (Mattar, 2017, p. 96).

\subsection{Mindset fixo e de crescimento}

Segundo Dweck (2006), existem dois tipos de mindset, que são basicamente definidos pela opinião que a pessoa adota a respeito de si mesma. O mindset fixo representa aquela pessoa que acredita que as suas qualidades são imutáveis. Profissionais com mindset fixo não reconhecem suas deficiências nem as corrigem. Para eles, a deficiência é intolerável. Chefes cruéis, controladores ou abusivos colocam todos os funcionários no mindset fixo. Os funcionários das empresas com mindset fixo afirmam que as organizações se caracterizam por fornecer menos apoio em relação aos riscos e à inovação (Dweck, 2006). Segundo Brown (2008), algumas ideias morrem porque não conseguem sobreviver em função da rejeição, principalmente, das organizações em que são originadas, mais do que rejeição do mercado.

O mindset de crescimento "se baseia na crença de que você é capaz de cultivar suas qualidades básicas por meio dos seus próprios esforços" (Dweck, 2006, p. 15). As empresas com mindset de crescimento possuem líderes que acreditam no desenvolvimento humano. Os funcionários das empresas com mindset de crescimento são mais propensos a dizer que suas organizações os apoiam a assumir riscos calculados, inovação e criatividade. (Dweck, 2006).

Para Knowles et al. (2005), quando o clima institucional da organização estimula o autoaperfeiçoamento, é provável que se verifique um alto engajamento nas atividades de aprendizagem. Nas organizações estruturadas hierarquicamente, verifica-se menor motivação para o autoaperfeiçoamento e mais bloqueios no aprendizado do que nas organizações estruturadas funcionalmente ou por projetos. No modelo andragógico, a configuração do ambiente organizacional é o fator mais importante para o aprendizado a ser considerado pelas estruturas de desenvolvimento de recursos humanos (Knowles et al., 2005). Para Brown (2018, p. 66), "é necessário conceder a uma equipe criativa, o tempo, o espaço e o orçamento para cometer erros". O aprendizado pela descoberta é favorecido pelo clima psicológico que estimula a experimentação e é tolerante a erros, desde que algo seja aprendido (Knowles et al., 2005).

\section{Metodologia}

Esta pesquisa é aplicada, exploratória, de campo e com abordagem qualitativa (Bogdan \& Biklen, 2007; Creswell \& Creswell, 2018; Creswell \& Guetterman, 2019; Merriam \& Tisdell, 2016; Patton, 2015).

\subsection{Participantes}

Participaram do estudo nove profissionais, representados neste artigo pela letra $E$ mais um número $(E+n)$, de diferentes setores da economia: instituição de ensino superior (E1), telecomunicações (E2), serviços (E3, E5 e E9), educação (E4), indústria de autopeças (E6 e E7) e indústria aeronáutica (E8). O motivo para o convite para participar da pesquisa foi ancorado no conhecimento prático dos profissionais em relação à abordagem design thinking.

\subsection{Instrumento}

A entrevista semiestruturada foi o procedimento elegido para coleta de dados. Optou-se pela elaboração do instrumento com desenho flexível, considerando-se as orientações de Rubin e Rubin (2011). O instrumento envolveu um roteiro com 17 questões abertas, cujas questões visavam a compreensão do ponto de vista dos entrevistados sobre os principais temas da pesquisa, isto é, design thinking, competências, mindset e metodologias ativas de ensino-aprendizagem

A validação do instrumento aconteceu em três ocasiões no período de abril a maio de 2019. Participaram da validação do instrumento moderadores de design thinking e alunos do programa de estudos pós-graduados stricto sensu de Tecnologias 
da Inteligência e Design Digital da Pontifícia Universidade Católica de São Paulo. O projeto de pesquisa e o instrumento foram aprovados pelo Comitê de Ética em Pesquisa da PUC/SP, a partir do parecer consubstanciado CAAE: 13833919.1.0000.5482, no parecer: 3.346.787, em 24 de maio de 2019.

\subsection{Coleta de dados}

As entrevistas foram realizadas presencialmente e/ou a distância, conforme a agenda do entrevistado. Os entrevistados foram inquiridos sobre o papel que desempenhavam nas sessões de design thinking e explicaram que o papel poderia variar de sessão para sessão; poderiam atuar, por exemplo, em algumas situações, no papel de moderador e, em outras situações, no papel de participante. Os papéis foram citados com a seguinte frequência: a) facilitador (sete profissionais); b) participante (seis profissionais); c) stakeholders (três profissionais).

As gravações em áudio, para cada entrevista, tiveram uma duração média de 60 a 90 minutos e produziram um corpus transcrito de aproximadamente 55.248 palavras.

\subsection{Análise dos dados}

A pesquisa seguiu os critérios de codificação dos dados descritos por Saldaña (2013). Os 32 perfis de métodos de codificações e as suas possibilidades analíticas foram examinados, sendo selecionados três métodos para codificação e apresentação dos dados neste artigo: codificações provisória, de versus e de hipóteses.

Segundo Saldaña (2013), a codificação provisória estabelece um conjunto predeterminado de códigos antes do início da pesquisa de campo, gerado a partir de: revisões de literatura relacionadas ao estudo; achados de pesquisas anteriores; trabalho de campo piloto; conhecimento prévio do pesquisador e dados experimentais; e hipóteses formuladas pelo pesquisador, dentre outros. A codificação de versus identifica, em termos dicotômicos ou binários, os indivíduos, grupos, sistemas sociais, organizações, fenômenos, processos e conceitos em conflito direto entre si; é apropriada aos estudos de política, pesquisas de avaliação, análises críticas de cursos e conjuntos de dados qualitativos que sugerem fortes conflitos ou objetivos conflitantes entre os participantes. Já a codificação de hipóteses é a aplicação de uma lista de códigos prédeterminada para dados qualitativos, que almeja avaliar uma hipótese gerada previamente pelo pesquisador; os códigos são desenvolvidos a partir de uma teoria ou de uma previsão do que será encontrado nos dados e organizados em um esquema, antes que sejam coletados ou analisados.

\section{Resultados}

As respostas que os entrevistados forneceram sobre competências foram analisadas por meio da codificação provisória (Saldaña, 2013) e trouxeram informações sobre: as competências necessárias ao profissional na época atual; competências necessárias para atuar nas sessões de design thinking; autodesenvolvimento das competências; e competências desenvolvidas a partir da participação no programa de treinamento que utilizou a metodologia design thinking. Para a contabilização da frequência total de citações das competências, os seguintes critérios foram adotados para a mensuração dos dados apresentados nas Tabelas 1, 2 e 3: a) foram identificadas as competências mencionadas, por cada entrevistado, nas respostas a cada questão; b) independentemente da quantidade de vezes que o entrevistado citou a mesma competência em sua resposta a uma questão, considerou-se apenas uma citação por questão; c) o resultado total de citações de determinada competência foi alcançado a partir da soma das citações de todos os entrevistados nas respostas das quatro questões sobre competências realizadas, respeitando-se o critério explicado no item "b". 
Tendo em vista o interesse em compreender o ponto de vista dos entrevistados sobre as competências necessárias aos profissionais do século XXI e sua correlação com o design thinking, as questões 1,7 e 10 foram apresentadas e estão descritas na Tabela 1.

Tabela 1 - Quantidade de entrevistados que citaram as competências previamente selecionadas pelos autores nas questões 1,7 e 10 .

\begin{tabular}{|c|c|c|c|}
\hline $\begin{array}{l}\text { Competências } \\
\text { previamente } \\
\text { selecionadas }\end{array}$ & $\begin{array}{l}\text { 1. Considerando a perspectiva } \\
\text { do século XXI no cenário } \\
\text { social e organizacional, de } \\
\text { grandes transformações e } \\
\text { fluidez, quais são as mais } \\
\text { importantes competências, do } \\
\text { profissional desta época? }\end{array}$ & $\begin{array}{l}\text { 7. Quais as principais } \\
\text { competências, habilidades, } \\
\text { atitudes que o profissional } \\
\text { deveria apresentar para } \\
\text { contribuir para o sucesso de } \\
\text { uma sessão ou processo de } \\
\text { design thinking? }\end{array}$ & $\begin{array}{l}\text { 10. Como você } \\
\text { compararia alguma das } \\
\text { competências que você } \\
\text { mencionou (na questão } 7 \text { ) } \\
\text { com o seu } \\
\text { autodesenvolvimento? } \\
\text { Fale de sua experiência. }\end{array}$ \\
\hline Colaboração & 3 & 5 & 2 \\
\hline Comunicação & 2 & 5 & 4 \\
\hline Criatividade & 6 & 6 & 1 \\
\hline Empatia & 5 & 9 & 2 \\
\hline Inovação & 0 & 0 & 0 \\
\hline $\begin{array}{l}\text { Pensamento } \\
\text { crítico }\end{array}$ & 0 & 0 & 0 \\
\hline
\end{tabular}

A questão 12 tinha como objetivo entender se o entrevistado já havia participado de algum treinamento no qual tivesse identificado alguma das etapas do design thinking, enquanto metodologia de ensino-aprendizagem. Do total de entrevistados, oito profissionais responderam afirmativamente. Na sequência, pela questão 13, foi solicitado que esses oito profissionais refletissem sobre quais competências foram de alguma maneira impactadas por esse programa de treinamento (Tabela 2).

Tabela 2 - Quantidade de entrevistados que indicaram o desenvolvimento de algumas das competências pré-selecionadas em função do programa de treinamento com metodologia design thinking.

\begin{tabular}{lcc} 
Competências previamente selecionadas & Quantidade de Entrevistados & Entrevistado \\
\hline Colaboração & 3 & E2, E7 e E8 \\
Comunicação & 3 & E2, E7 e E8 \\
Criatividade & 1 & E5 \\
Empatia & 2 & E4 e E7 \\
Inovação & 0 & - \\
Pensamento crítico & 1 & E7
\end{tabular}

Fonte: Autores.

Tendo em vista o formato aberto das questões do roteiro de entrevista, os entrevistados, além de citar as competências previstas, mencionaram em suas respostas diferentes competências (Tabela 3). 
Tabela 3 - Competências não previstas previamente e frequência de citações considerando a soma questões 1, 7, 10 e 13 .

Competências não previstas

Capacidade de arriscar/ Assumir risco

Relacionamento interpessoal

Comprometimento/ Responsabilidade/ Accountability

Ter Flexibilidade/ Ser Multitarefada/ Multifuncional

Open mind/ Não julgar/ Evitar travas mentais

\section{Frequência de citações}

5

5

6

6

9

Fonte: Autores.

A codificação de hipóteses apoiou a realização de um comparativo entre as três hipóteses previamente elaboradas pelos autores e os relatos dos nove entrevistados. A hipótese B foi analisada pela codificação de versus e pela codificação de hipóteses.

A hipótese A afirma que a prática da abordagem design thinking contribui para o desenvolvimento das competências necessárias ao profissional independentemente das ações da área de educação corporativa. Os entrevistados E2, E4, E5, E6 e E7 apresentaram, dentre as várias competências, algumas das competências previamente selecionadas pelos autores, tais como: colaboração, criatividade, comunicação e empatia; enquanto os entrevistados E1 e E9 confirmaram o desenvolvimento de competências diferentes das previamente previstas, como, por exemplo: autoconsciência, resolução de problemas e open mind. Os entrevistados E3 e E8 não correlacionaram o autodesenvolvimento de competências com a participação nas sessões de design thinking.

A hipótese B declara que a metodologia de ensino-aprendizagem design thinking traz resultados mais expressivos, nas ações de educação corporativa, do que as metodologias tradicionais. Na análise da codificação de versus, foram consideradas as respostas dos entrevistados E1, E2, E5 e E9, que fizeram o comparativo entre os resultados de um programa de treinamento que contivesse dinâmicas do design thinking e outro programa de metodologia tradicional. Os dados apontam que, na opinião desses entrevistados, o ensino tradicional proporciona baixa ou nenhuma retenção de conhecimento e a metodologia design thinking promove a fixação do conteúdo/aprendizagem por se tratar de uma metodologia prática. Na análise da codificação de hipóteses, foram considerados as entrevistas que não apresentam comparativos, mas que trazem o ponto de vista dos entrevistados sobre uma ou outra metodologia de ensino-aprendizagem. Para os entrevistados E3 e E6, as metodologias tradicionais não contribuem para a aquisição de competências que demandam prática. Na opinião de E1 e E2, a utilização da metodologia design thinking promove, pela aplicação prática da abordagem, o desenvolvimento de algumas competências, como colaboração, criatividade, desprendimento e empatia. E8 acredita que o design thinking proporciona fixação da aprendizagem, já que envolve a prática.

A hipótese $\mathrm{C}$ afirma que os mindsets — individual e organizacional — interferem no desenvolvimento das competências dos profissionais. Aos entrevistados, foi perguntado, na questão 16, o que, segundo a experiência deles, poderia interferir no desenvolvimento das competências: pensamento crítico, empatia, comunicação, colaboração, criatividade e inovação. Foi verificado que alguns profissionais usaram palavras diferentes para se referir ao ambiente organizacional, como hierarquia, mensuração de resultados e reconhecimento, e, no processo de análise dos dados, os autores relacionaram essas expressões ao conceito de mindset da empresa ou organização. Já expressões como "estilo de liderança e "a pessoa querer" foram relacionadas com o conceito de mindset da liderança e da própria pessoa, respectivamente. Os entrevistados E1, E2, E3, E6, E7 e E9 apresentaram justificativas relacionadas ao mindset fixo do ambiente ou da liderança a quem o profissional se 
subordina, como fatores que podem interferir no desenvolvimento das competências dos profissionais. E4, E5, E8 e, novamente, E6 e E9, apresentaram justificativas relacionadas ao mindset fixo do próprio profissional.

\section{Discussão}

\subsection{Discussão sobre competências}

O roteiro da entrevista continha apenas perguntas abertas e, como consequência, os dados obtidos foram amplos. Um total de 61 competências foram mencionadas pelos entrevistados, considerando as respostas às questões 1, 7, 10 e 13. Desse total, 56 competências foram agrupadas, por afinidade de sentido, e resultaram em uma lista com 40 competências exclusivamente apresentadas pelos entrevistados, além de cinco das seis competências previamente previstas pelos autores (colaboração, criatividade, comunicação, empatia e pensamento crítico).

Criatividade (EC, 2018; Battelle for Kids, 2019; WEF, 2018) foi mencionada por seis entrevistados nas respostas às questões 1 (competências para profissionais da época atual) e 7 (competências para design thinking). $\mathrm{O}$ entendimento dos entrevistados sobre a competência criatividade está alinhado com a definição escolhida para o artigo, como comprova a citação a seguir.

Isso é porque no fim pra se adequar às essas mudanças e para buscar essas inovações é preciso ter uma criatividade e uma, como eu posso dizer ... conseguir trabalhar com o que é incerto. Com o risco de errar ... ser criativo para propor novas soluções e também tentar absorver que muitas das vezes essas soluções propostas elas não vão dar certo, né? (E2).

A competência colaboração (EC, 2018; Battelle for Kids, 2019) foi citada por cinco entrevistados na questão 7, e por três entrevistados na questão 1 . Os comentários realizados reiteram a sinergia entre a definição da competência escolhida para o artigo e a compreensão dos entrevistados sobre a capacidade de trabalhar em conjunto.

Eu acho que é o que vai fazer a diferença aqui é: a criatividade, a capacidade de criar; a capacidade de arriscar e fazer novas coisas acontecerem; é a capacidade de trabalhar em conjunto, não vamos mais conseguir trabalhar sozinho; é a capacidade de trabalhar, de ter essa relação do ganha-ganha. (E3).

A competência comunicação (EC, 2018; Battelle for Kids, 2019) foi citada como necessária por cinco entrevistados nas sessões de design thinking (questão 7), e ao profissional desta época (questão 1) citada por dois entrevistados. O relato dos entrevistados condiz com a definição escolhida e destaca a habilidade de comunicação oral, escrita e verbal em diversos contextos.

Saber fazer as perguntas certas ... O saber se conectar com o humano ... Eu acho que esse é o principal ponto que eu vejo nos dias de hoje. Fora criatividade, empatia, enfim o saber desenrolar uma ideia. Eu acho isso importante. (E7).

Empatia, entendida como a capacidade de entender o mundo pela perspectiva do outro (EC, 2018) e, como competência comum ao design thinker (Brown, 2008), foi mencionada pelos nove entrevistados nas respostas à questão 7 e por cinco profissionais nas respostas à questão 1 , o que demonstra a importância da competência para o profissional e o ambiente de trabalho. 
A própria relação interpessoal. Habilidade em trabalhar em equipe ... Compreensão, paciência, empatia, tentar entender a dificuldade do colega do lado. (E4).

A competência pensamento crítico é citada nas quatro estruturas internacionais de competências, indicadas no Quadro 1, e foi mencionada pela entrevistada E5, em sua resposta à questão 13. Uma possível razão para pensamento crítico não ter sido lembrada com maior ênfase pelos entrevistados, é a associação, que no senso comum se faz, da palavra crítico à ideia de desaprovação, sendo que uma das práticas mais enfaticamente divulgadas na literatura sobre o papel do design thinker é a atitude de não julgar (Doorley et al., 2018). Esta hipótese pode ser parcialmente comprovada pela frequência de menções, 9 no total, às competências de não julgar, open mind e não julgamento, conforme Tabela 3.

A competência inovação não foi mencionada pelos entrevistados, apesar de fazer parte das estruturas de competência internacionais WEF (2018), EC (2018) e Battelle for Kids (2019). Uma explicação para este fato pode estar relacionada ao entendimento, por parte desses profissionais, que inovação é uma função da empresa associada ao produto ou ao processo da organização (Gattermann Perin et al., 2007), e não uma competência relacionada à pessoa ou ao profissional. (Battelle for Kids, 2019; EC, 2018).

Os resultados demonstram que, no entendimento deste grupo de entrevistados, formado por profissionais que moderam e participam de sessões e processos de design thinking, as competências de comunicação (citada 13 vezes), colaboração (14), criatividade (14) e empatia (19), no geral, foram as mais lembradas em relação às questões apresentadas, além das competências citadas mas não previstas pelos autores, tais como capacidade de arriscar (5), relacionamento interpessoal (5), comprometimento (6), flexibilidade (6) e open mind e não julgar (9).

\subsection{Discussão relacionada à hipótese $\mathrm{A}$}

Com o objetivo de verificar se a vivência dos entrevistados nos processos de design thinking promoveu o desenvolvimento de alguma competência necessária no cenário social e organizacional, as questões 1,7 e 10 foram feitas. Sete dos nove profissionais entrevistados verbalizaram o desenvolvimento de alguma competência, especificamente a partir da sua atuação nas sessões de design thinking, sendo que, desses sete profissionais, cinco entrevistados indicaram o desenvolvimento de alguma das competências previamente selecionadas pelos autores, que foram: a) comunicação (4 citações); b) colaboração (2); c) empatia (2); e d) criatividade (1). Outras competências, não previstas pelos autores, foram também apresentadas pelos entrevistados como tendo sido desenvolvidas a partir da atividade prática com design thinking, dentre elas: capacidade de síntese, open mind, não desistir, cooperação, desenvolver uma ideia com profundidade, liderança, paciência e relacionamento interpessoal.

O entrevistado E9 comenta que o design thinking lhe proporcionou uma ruptura com o mindset tradicional, especializado (Le Boterf, 2003), levando-o a adotar um mindset "generalizado". Afirma que o design thinking o empoderou para uma atitude de enfrentamento e resolução de problemas (WEF, 2018; EC, 2018; Battelle for Kids, 2019; OECD.Stat, 2019), open mind e abertura para a superação dos desafios que surgem em diversas áreas de sua vida.

Aqui o design thinking, ele trouxe uma ruptura pelo menos a vivência para mim, uma ruptura desse mindset de tão especializado para um mindset mais generalizado, onde, assim como na vida eu sou um ser humano frente a problemas diversos, no trabalho eu também sou. Eu sou capaz, e projetos de design thinking mostram isso, que os seres humanos são capazes de fazer coisas incriveis quando eles simplesmente ficam abertos a resolvê-los. (E9). 
E5 relata o desenvolvimento de algumas competências a partir da prática do design thinking, dentre elas: comunicação (EC, 2018; Battelle for Kids, 2019), não julgar e ouvir diferentes pontos de vista, que são cada vez mais imprescindíveis para a fluidez dos ambientes e para as relações de trabalho (Gonzalez Vazquez et al., 2019), além da visão generalista, ampliada e estratégica do negócio, alinhada com o conceito de economia do saber de Le Boterf (2003).

Dá pra mencionar: comunicação, a partir do momento que você precisa se expressar nesses grupos, você tem que colocar a sua ideia com assertividade, você tem que aprimorar a sua comunicação. Então eu consigo ver que a minha comunicação melhorou bastante. ... O não julgar, ouvir pontos de vista diferentes, a sua visão generalista aumenta muito, independente do negócio. ... Então você começa a ter uma visão ampliada do negócio, eu acho que visão estratégica também, dependendo dos trabalhos que são feitos você consegue ter uma visibilidade do negócio como um todo não operacional, mas estratégico. ... Então eu acho que esses são os principais pontos que eu considero como desenvolvimento que aconteceram comigo. (E5).

E5 apresenta a experiência na moderação de uma sessão de design thinking crítica entre um grupo de funcionários da empresa e profissionais de um fornecedor, na busca de soluções para um problema (Fabri, 2015; Melo \& Abelheira, 2015). O processo exigiu muita habilidade do moderador para atingir os resultados e superar conflitos (Le Boterf, 2003), além de promover o aprendizado prático daqueles que não conheciam a abordagem (Kolb, 1984; Filatro et al., 2019).

Eu lembro de uma situação com um fornecedor ... e foi difícil, o começo, mas depois que eles viram que tudo vai sendo construído em conjunto, que prevalece todos os lados e não só um lado, a coisa fluiu de uma forma tão boa, tão boa, que eles pediram desculpas de terem levado 20 pessoas para a sala. ... Era um workshop para construir soluções, ideias, soluções. E eles tinham uma problemática lá. Mas como a construção foi feita em conjunto, um apoiando o outro, foi muito bom. (E5).

E7, por sua vez, menciona o desenvolvimento das competências de liderança (WEF, 2018; Battelle for Kids, 2019), comunicação, persistência, ter paciência, resiliência (EC, 2018) e empatia (Lee \& Benza, 2015; EC, 2018).

Olha, eu de 2016 pra cá, mudei muito. Eu acho que a prática da metodologia me ajudou a adquirir também essas competências. ... essa questão de não desistir, de ir a fundo, essa questão da liderança, acho que é um ponto super importante também de trazer. ... Aí acho que a habilidade de comunicação também ... (E7).

O entrevistado E6, na sua resposta, exemplifica como a experiência de campo, aplicando o design thinking, lhe trouxe aprendizado (Kolb, 1984; Le Boterf, 2003; Filatro et al., 2019), principalmente um mindset calcado na empatia.

Eu acho que o profissional foi muito engraçado porque agora eu sempre penso no usuário. É fato, que tudo eu vou falar: 'mas gente, e o usuário?'. Então muda muito mais. Esses dias a gente foi fazer um brinde, e eu falei para a pessoa de comunicação, 'mas, será que o usuário gosta disso?' A pessoa, 'nossa é verdade'. Eu acho que isso muda muito nossa, nossa percepção do dia a dia. ... Muda o mindset. (E6).

E3 foi a única entrevistada que afirmou que o design thinking não lhe proporcionou o desenvolvimento de competências e atitudes. 


\subsection{Discussão relacionada à hipótese $B$}

A hipótese B afirma que a metodologia de ensino-aprendizagem design thinking tem resultados superiores ao das metodologias tradicionais, em educação corporativa. Esta hipótese é confirmada por oito entrevistados, para quem o design thinking gera impactos superiores às metodologias tradicionais no desenvolvimento de competências, habilidades ou atitudes dos profissionais. Um total de cinco profissionais confirmou o desenvolvimento de alguma(s) da(s) competência(s) préselecionada(s) pelos autores, além de outras competências.

O entrevistado E6 relata a experiência do curso de graduação, quando assistiu a uma aula teórica ou tradicional (Knowles, Holton, \& Swanson, 2005) sobre design thinking. E6 e E9 compreendem que a metodologia tradicional mantém os alunos em uma atitude passiva, o que dificulta a absorção dos conhecimentos (Cavalcanti \& Filatro, 2016; Mattar, 2017).

Porque na faculdade eu tive design thinking, mas como matéria. Na faculdade. Só teórico. Super vazio. As pessoas não entendiam porque elas estavam lá. Isso é triste, sabe? (E6).

E1 e E8, por meio de suas falas, destacam as vantagens das metodologias ativas, que pressupõem a participação dos alunos no processo de aprendizagem (Filatro et al., 2019; Mattar, 2017), proporcionam retenção do conhecimento a partir da transformação da experiência em conhecimento (Kolb, 1984) e fornecem recursos para os adultos lidarem com as situações da vida real (Knowles; Holton \& Swanson, 2005).

Nesse sentido, com experiências didáticas, eu acho que o design thinking tem o poder de causar assim uma pregnância, fixação, memória. Tudo o que a gente aprende através da prática, através de exercícios, é ele é melhor fixado. ... Então eu acho que de uma maneira geral, a experiência de aprendizado fica mais interessante. Sabe? (E8).

E2 relata uma experiência na qual o design thinking, aplicado em um treinamento, proporcionou um clima colaborativo e de criatividade na sala de aula (Mattar, 2017; Lynch et al., 2019), gerando fixação do conteúdo, sentimentos e da experiência como um todo.

Então, esse treinamento que eu fiz foi em 2013, mas ainda eu tenho vivo na minha cabeça como foi o processo porque acaba despertando alguns sentimentos e discussões e então tem essa troca naquele grupo que está sendo discutido o tema, tem as opiniões, e tem a maneira de abordar, e então acaba tendo uma riqueza de sentimentos e discussões que se a gente for num treinamento mais expositivo, que fica uma pessoa ali falando tal e com material escrito para você ler depois, você acaba não tendo isso, né? Então eu acho que isso contribui para fixar e você ver na prática a aplicação daquilo. (E2).

É possível afirmar que, muito embora nem todos os entrevistados tenham realizado a comparação entre as metodologias tradicional e o design thinking, nenhum entrevistado defendeu a utilização da metodologia tradicional para conteúdo de cunho prático ou para o desenvolvimento de competências. Segundo os entrevistados E1, E2, E5, E8 e E9, o design thinking, por seu caráter prático, gera resultados mais expressivos e contribui para a apreensão dos conteúdos, se comparado com a metodologia tradicional. Dois entrevistados criticaram o uso da metodologia tradicional (E3 e E6). 


\subsection{Discussão relacionada à hipótese $\mathrm{C}$}

Para compreender a visão dos entrevistados sobre o que poderia interferir, segundo sua experiência, no desenvolvimento das habilidades e competências pensamento crítico, empatia, comunicação, colaboração, criatividade e inovação, a questão 16 foi proposta.

Os entrevistados E4, E5, E6, E7 e E8 afirmaram que a pessoa que tem o mindset fixo acredita que as suas qualidades são imutáveis e não reconhece suas deficiências. Como consequência, não as corrige ou as desenvolve (Dweck, 2006).

Eu acho que ele mesmo. Ele mesmo não querer se adaptar ou não querer mudar para entrar nesse ciclo de mudança de conceito, de pensamento. Essa parte da própria pessoa mesmo, querer mudar ou não. (E4).

E1, E2 e E9 disseram acreditar que os líderes de mindset fixo ou diretivos e estruturas hierarquizadas (Dweck, 2006; Knowles, Holton, \& Swanson, 2005) bloqueiam o aprendizado (Knowles, Holton, \& Swanson, 2005) de competências.

Eu acho que o direcionamento da gestão, eu acho que, dependendo da maneira como isso é promovido dentro área, ou dentro da empresa, pode limitar. Ou seja, áreas um pouco mais operacionais e que tenham ali um escopo muito definido e direcionado, a pessoa acaba não tendo como propor algo diferente, ou buscar um tipo de outra solução. Mesmo que não seja uma área operacional, que tenha um gestor, um diretor que seja muito modelador, $e$ direcionador nas atividades, ele acaba interferindo e não permitindo que as pessoas que estão ali atuando $e$ trabalhando, consigam sugerir coisas, e buscar. (E2).

E3, E6 e E9 comentaram sobre a necessidade de o ambiente organizacional apoiar a experimentação, riscos e a criatividade como forma de desenvolver os profissionais; portanto, demonstram conexão com Dweck (2006) e Brown (2018).

Uma estrutura que não recompensa o risco, que não recompensa a criatividade e pelo contrário, às vezes, vê disso motivos de chacota ou vê disso motivos para, não sei, às vezes até repreensão do profissional, isso, sem dúvida, essas estruturas elas minam o processo de inovação, sem dúvida. (E9).

Pelos dados colhidos a partir das entrevistas realizadas, a Hipótese C foi confirmada, ou seja, na opinião de todos os profissionais entrevistados, o mindset fixo da pessoa, da liderança ou da organização pode interferir negativamente no desenvolvimento das competências dos profissionais.

\section{Conclusão}

\subsection{Implicações práticas}

A partir da triangulação dos dados com o referencial teórico da pesquisa e considerando os objetivos e as hipóteses previamente elaboradas, acredita-se que esta pesquisa possa contribuir para estimular a utilização da abordagem design thinking de uma forma mais ampla nas organizações. A abordagem design thinking, na opinião majoritária dos entrevistados, contribui para o desenvolvimento das competências pessoais e sociais dos profissionais, quando utilizada na resolução de conflitos, busca de soluções e concepção de novos produtos e serviços, e quando utilizada como metodologia ativa de ensinoaprendizagem nas ações de educação corporativa.

Pelos dados obtidos, verificou-se que ocorre o desenvolvimento de competências a partir da participação prática dos profissionais nas sessões e nos processos de design thinking, independentemente do papel que o profissional desempenhe nas 
atividades, sendo que as habilidades e competências desenvolvidas e mais frequentemente mencionadas foram: empatia, colaboração, comunicação, cooperação, criatividade, desenvolvimento de ideias, capacidade de síntese, não desistir, open mind, paciência e relacionamento interpessoal. O local de trabalho, as sessões e os processos de design thinking confirmaramse como espaços de aprendizado e desenvolvimento de competências para os profissionais.

A conexão do conteúdo e da abordagem de ensino com o mundo real e prático demonstra ser fundamental para o aprendizado e desenvolvimento dos profissionais. O design thinking, enquanto metodologia de ensino-aprendizagem, contribui para o desenvolvimento das competências e apresenta resultados superiores aos resultados da metodologia tradicional, segundo os dados obtidos. Acredita-se que a pesquisa possa contribuir também para estimular a utilização do design thinking nas ações da educação corporativa.

Uma outra contribuição desta pesquisa está relacionada com o entendimento de que o mindset fixo pode interferir negativamente no desenvolvimento das competências dos profissionais. Na opinião de todos os entrevistados, o desenvolvimento das competências pré-selecionadas pelos autores, isto é, pensamento crítico, empatia, comunicação, colaboração, criatividade e inovação, pode ser prejudicado em função da interferência do mindset fixo, seja o mindset do próprio profissional, dos gestores ou da empresa, com as suas políticas organizacionais. Esta constatação contribui, dentre outros pontos, para que a área de educação corporativa considere em seu planejamento uma análise prévia dos fatores externos que podem, por exemplo, afetar os resultados do processo de desenvolvimento das competências dos profissionais.

\subsection{Limitações}

A pesquisa teve algumas limitações, que podem ter influenciado, parcialmente, os dados obtidos, e, por consequência, as conclusões apresentadas. Uma delas foi a utilização da experiência pessoal passada dos entrevistados na identificação, segundo seus critérios pessoais, de programas de treinamento que apresentavam características da metodologia tradicional ou design thinking. Esta característica da pesquisa não permitiu a contribuição de um entrevistado que não se recordou de uma experiência de treinamento com a metodologia design thinking.

\subsection{Trabalhos Futuros}

A atual pesquisa centralizou sua averiguação sobre fatores que poderiam interferir, no sentido de prejudicar, o processo de design thinking ou o desenvolvimento de competências e habilidades, o que trouxe, segundo a opinião dos entrevistados, aspectos relacionados ao mindset fixo. Uma pesquisa futura poderia averiguar o ponto de vista dos profissionais sobre a influência do mindset de crescimento no desenvolvimento das sessões e no desenvolvimento das competências dos profissionais.

Uma segunda sugestão seria a realização de um experimento de campo, no qual o pesquisador poderia elaborar e conduzir um programa de treinamento, apoiado pela metodologia design thinking, e outro treinamento com características da metodologia tradicional. Essa vivência poderia trazer uma maior assertividade às análises dos profissionais sobre os benefícios de ambas as metodologias.

Caso a pesquisa fosse realizada especificamente em uma ou duas empresas, além do controle sobre as variáveis relacionadas aos programas de treinamentos, seria possível colher informações mais detalhadas sobre a influência do mindset no desenvolvimento de novas competências. Desta forma, os dados, por exemplo, sobre o impacto do ambiente de trabalho no desenvolvimento das competências dos profissionais, independentemente da utilização da metodologia de ensinoaprendizagem design thinking em ações de educação corporativa, poderiam ser analisados e comparados. 
A última sugestão para trabalho futuro refere-se ao estudo dos impactos da abordagem design thinking nos resultados do negócio das empresas que utilizam ou não a abordagem de forma simultânea, ou seja, como metodologia de ensino e como ferramenta para resolver problemas, conflitos ou conceber produtos e serviços.

\section{Referências}

Ananiadou, K., \& Claro, M. (2009). 21st Century Skills and Competences for New Millennium Learners in OECD Countries. OECD Education Working Papers, 41, OECD Publishing. https://doi.org/10.1787/218525261154

Battelle for Kids. (2019). Partnership for 21st Century Learning. Framework for 21st Century Learning Definitions. Battelle for Kids. https://www.battelleforkids.org/learning-hub/learning-hub-item/framework-for-21st-century-learning-definitions

Bogdan, R. C., \& Biklen, S. K. (2007). Qualitative research for education: an introduction to theories and methods (5a ed.). Pearson.

Brown, T. (2008). Design thinking. Harvard Business Review, 86(6), 84.

Brown, T. (2018). Design Thinking: uma metodologia poderosa para decretar o fim das velhas ideias. Alta Books Editora.

Cavalcanti, C. C., \& Filatro, A. (2016). Design thinking na educação presencial, a distância e corporativa. Saraiva.

Creswell, J. W., \& Creswell, J. D. (2018). Research design: qualitative, quantitative, and mixed methods approaches (5a ed.). Sage.

Creswell, J. W., \& Guetterman, T. C. (2019). Educational research: planning, conducting, and evaluating quantitative and qualitative research (6th ed.). Pearson.

Doorley, S., Holcomb, S., Klebahn, P., Segovia, K., \& Utley, J. (2018). Design Thinking bootleg, dSchool. Institute of Design at Stanford. https://dschool.stanford.edu/resources/design-thinking-bootleg

Dweck, C. (2006). Mindset: A nova psicologia do sucesso. Objetiva.

EC - European Commission. (2018). Commission staff working document accompanying the document Proposal for a Council Recommendation on Key Competences for Lifelong Learning. https://eur-lex.europa.eu/legal-content/EN/TXT/PDF/?uri=CELEX:52018SC0014\&from=EN

Fabri M. (2015). Thinking with a New Purpose: Lessons Learned from Teaching Design Thinking Skills to Creative Technology Students. In: Marcus A. (Eds.), Design, User Experience, and Usability: Design Discourse. Lecture Notes in Computer Science. Springer, Cham, 9186, 32-43. https://doi.org/10.1007/978-3-319-20886-2_4

Filatro, A., Costa, C. C., de Azevedo Junior, D. P., \& Nogueira, O. (2019). Design instrucional 4.0. Saraiva.

Gattermann Perin, M., Hoffmann Sampaio, C., \& Hooley, G. (2007). Impacto dos recursos da empresa na performance de inovação. Revista de Administração de Empresas, 47(4), 1-13. http://dx.doi.org/10.1590/S0034-75902007000400005

Gonzalez Vazquez, I., Milasi, S., Carretero Gomez, S., Napierala, J., Robledo Bottcher, N., Jonkers, K., \& Cabrera Giraldez, M. (2019). The changing nature of work and skills in the digital age (No. JRC117505). Joint Research Centre (Seville site). 10.2760/679150

Knowles, M. S., Holton, E., \& Swanson, R. (2005). The adult learner: the definitive classic in adult education and human resource development (6th ed.). MA: Elsevier.

Kolb, D. A. (1984). Experiential learning: experience as the source of learning and development. Prentice Hall.

Le Boterf, G. (2003). Desenvolvendo a competência dos profissionais. Artmed.

Lee, C., \& Benza, R. (2015). Teaching Innovation Skills: Application of Design Thinking in a Graduate Marketing Course. Business Education Innovation Journal, 7(1), 43-50.

Lynch, M., Kamovich, U., Longva, K. K., \& Steinert, M. (2019). Combining technology and entrepreneurial education through design thinking: Students' reflections on the learning process. Technological Forecasting and Social Change, 119689. https://doi.org/10.1016/j.techfore.2019.06.015

Mattar, J. (2017). Metodologias ativas para a educação presencial, blended e a distância. Artesanato Educacional.

Melo, A., \& Abelheira, R. (2015). Design Thinking \& Thinking Design: Metodologia, ferramentas e uma reflexão sobre o tema. Novatec.

Merriam, S. B., \& Tisdell, E. J. (2016). Qualitative research: a guide to design and implementation (4a ed.).Jossey-Bass.

OECD.STAT. Web Browser. (2019). Skill needs. OECD.Statistics. https://stats.oecd.org/Index.aspx?DataSetCode=SKILLS_2018_TOTAL

OECD - Organization for Economic Co-operation and Development. (2018). Skills for Jobs. OECD.ahttps://www.oecdskillsforjobsdatabas e.org/data/Skills\%20SfJ_PDF\%20for\%20WEBSITE\%20final.pdf.

Patton, M. Q. (2015). Qualitative research \& evaluation methods: integrating theory and practice (4a ed.). Sage.

Reisch, F. A. M., \& Dalmau, M. B. L. (2020). Trilhas de aprendizagem e o desenvolvimento de competências gerenciais: um estudo de caso no Instituto Federal Catarinense - IFC. Research, Society and Development, 9(7): 1-32. 
Research, Society and Development, v. 10, n. 5, e31210514949, 2021

(CC BY 4.0) | ISSN 2525-3409 | DOI: http://dx.doi.org/10.33448/rsd-v10i5.14949

Rubin, H. J., \& Rubin, I. S. (2011). Qualitative interviewing: The art of hearing data. Sage.

Saldaña, J. (2015). The coding manual for qualitative researchers. Sage.

WEF — World Economic Forum. (2018). The Future of Jobs Report. http://www3.weforum.org/docs/WEF_Future_of_Jobs_2018.pdf. 